\title{
Enoxacin with UVA Irradiation Induces Apoptosis in the AsPC1 Human Pancreatic Cancer Cell Line Through ROS Generation
}

\author{
KOJI NISHI, MEGUMI KATO, SAKI SAKURAI, AYAKO MATSUMOTO, \\ YUMIKO IWASE and NAGAHIKO YUMITA \\ Laboratory of Drug Metabolism and Pharmacotherapeutics, \\ Department of Clinical Pharmacy, Yokohama University of Pharmacy, Kanagawa, Japan
}

\begin{abstract}
Pancreatic cancer is one of the deadliest human cancers. In the current study, we investigated the possibility of a new treatment strategy using a combination of the new fluoroquinolone, enoxacin, and mild ultraviolet A (UVA) irradiation. Enoxacin with UVA irradiation increased the number of annexin V-positive (apoptotic) pancreatic cancer cells in time- and concentration-dependent manners, whereas alone neither had these effects. In addition, enoxacin with UVA irradiation induced cleavage of poly (ADP-ribose) polymerase in AsPCl human pancreatic cancer cells. Moreover, the singlet oxygen scavengers, histidine and sodium azide, and the hydroxyl radical scavenger, mannitol, significantly suppressed apoptosis induced by enoxacin and UVA irradiation, respectively. These results suggest that UVA irradiation activates enoxacin, after which activated enoxacin induces apoptosis of AsPCl cells through generation of reactive oxygen species. Therefore, the combination of enoxacin with mild UVA irradiation may be a useful method for treating pancreatic cancer.
\end{abstract}

Pancreatic cancer is the fifth leading cause of cancer-related mortality in Japan. Although the standard chemotherapy regimens, FOLFIRINOX (fluorouracil, leucovorin, irinotecan and oxaliplatin), gemcitabine and nab-paclitaxel, are widely used to treat patients with advanced pancreatic cancer, their antitumor effects (progression and survival rates) are less potent against this cancer type than other solid tumors $(1,2)$.

The most common form of ultraviolet (UV) radiation is sunlight, which produces three main types of radiation

Correspondence to: Koji Nishi, Laboratory of Drug Metabolism and Pharmacotherapeutics, Department of Clinical Pharmacy, Yokohama University of Pharmacy, 601 Matano-cho, Totsuka-ku, Yokohama, Kanagawa 245-0066, Japan. Tel: +81 458591300, Fax: +81 458591301, e-mail: k.nishi@hamayaku.ac.jp

Key Words: Apoptosis, enoxacin, pancreatic cancer, AsPC1. according to their wavelength: UVA, UVB, and UVC; UVA constitutes $95 \%$ of the radiation that reaches the Earth's surface. Although UVA and UVB are well-known human carcinogens (3-5), UVA is a much weaker form of UV radiation and is therefore less harmful. In fact, Kimura et al. reported that UVA did not induce apoptosis of cancer cells even when the dose was increased to $200 \mathrm{~J} / \mathrm{m}^{2}$ (6). On the other hand, UVA causes photoallergic reactions in patients administered fluoroquinolone drugs such as enoxacin, but the mechanism underlying these effects remains unknown (7). We considered the possibility that UVA radiation could be used for the treatment of cancer in the form of photodynamic therapy (PDT). Several drugs have been investigated for their ability to act as photosensitizing agents for PDT; these drugs were found to induce apoptosis of cancer cells (8-10).

In this study, we explored the possibility of whether the novel fluoroquinolone derivative enoxacin might be a candidate photosensitizer for PDT of pancreatic cancer. To this end, we evaluated whether enoxacin induces apoptosis of the pancreatic cancer cell line, AsPC1, under the conditions of mild UVA irradiation, which causes less damage to cells. We then discussed the mechanism and possibility of our results being useful for the development of new therapeutic strategies for pancreatic cancer.

\section{Materials and Methods}

Cell culture and reagents. The human pancreatic cancer cell line, AsPC1, was obtained from the American Type Culture Collection (Manassas, VA, USA). The cells were cultured in the recommended RPMI-1640 medium supplemented with $10 \%$ heat-inactivated fetal calf serum (Gibco, Invitrogen, Carlsbad, CA, USA), $100 \mathrm{U} / \mathrm{ml}$ penicillin, and $100 \mathrm{pg} / \mathrm{ml}$ streptomycin (Sigma, St. Louis, MO, USA) in $95 \%$ humidified air and $5 \%$ carbon dioxide at $37^{\circ} \mathrm{C}$. Enoxacin was purchased from LKT Laboratories, Inc. (St. Paul, MN, USA). Histidine, mannitol, and superoxide dismutase (SOD) were purchased from Wako Pure Chemical Industries Ltd. (Osaka, Japan). Sodium azide (NaN3) was purchased from Sigma. The other chemicals used were purchased from commercial suppliers. 
A

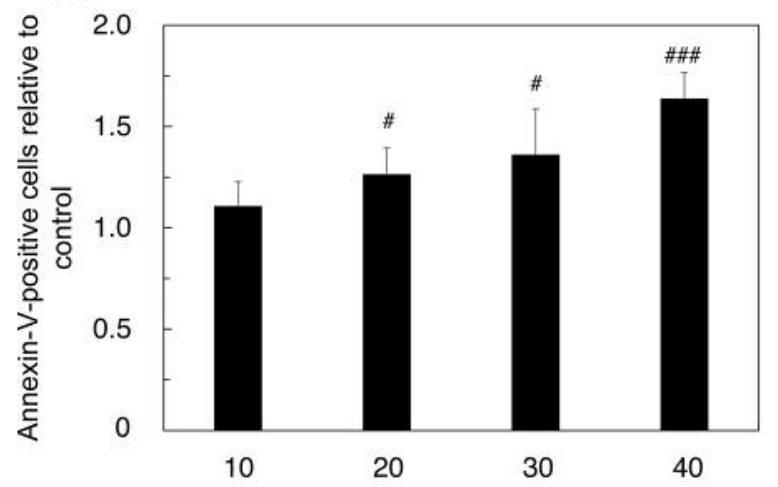

UV irradiation time (min)

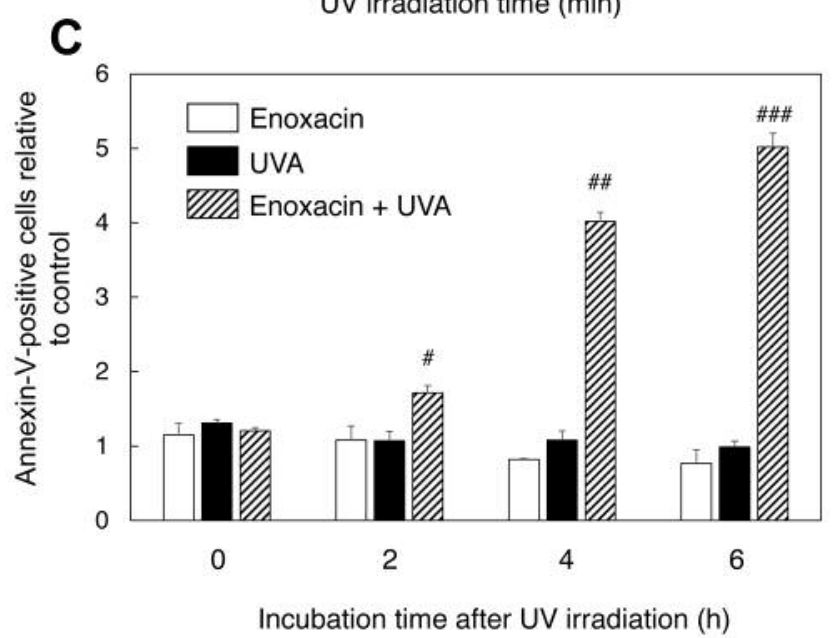

B

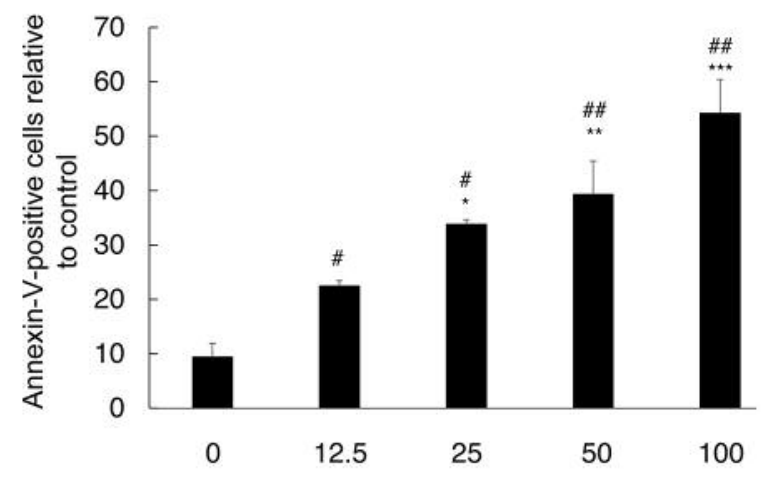

D

Enoxacin concentration $(\mu \mathrm{M})$

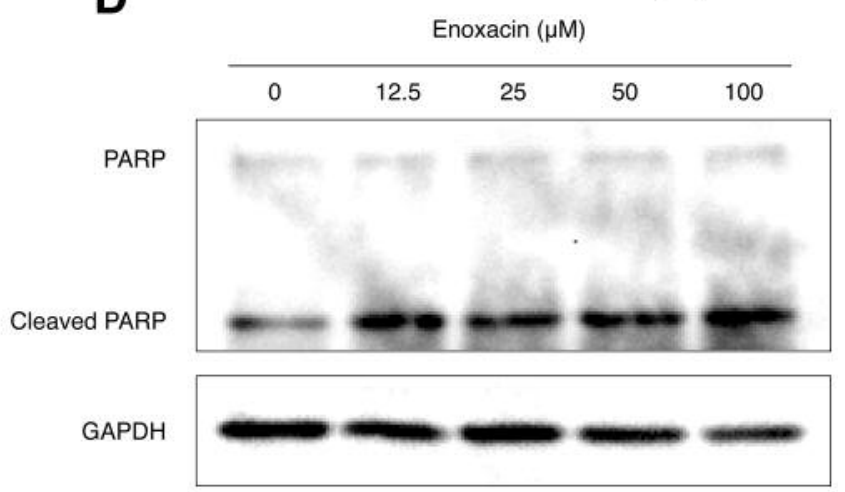

Figure 1. Induction of apoptosis in AsPC1 cells by enoxacin combined with UVA irradiation as quantified using a MUSE cell analyzer. A: Cells were treated with UVA irradiation with or without $100 \mu \mathrm{M}$ enoxacin for 10, 2030 or $40 \mathrm{~min}$. Apoptotic cells were quantified at $4 \mathrm{~h}$ after UVA irradiation. B: Cells were treated with or without $100 \mu \mathrm{M}$ enoxacin under UVA irradiation for $20 \mathrm{~min}$. Apoptotic cells were quantified at 0, 2, 4, and 6 h after UV irradiation. C: Cells were treated without or with 12.5, 25, 50, and $100 \mu M$ enoxacin under 20 min UVA irradiation. Apoptotic cells were quantified at $4 \mathrm{~h}$ after UV irradiation. Ds. Western blot of the effects of enoxacin $(0,12.5,25,50$, and $100 \mu M)$ with UVA irradiation on poly (ADP-ribose) polymerase (PARP) cleavage. AsPC1 cells were treated with $100 \mu M$ enoxacin and 20 min UVA irradiation, and then quantified at $4 \mathrm{~h}$ after UV irradiation. Cell lysates were then analyzed by western blotting to detect levels of total and cleaved PARP, as described in the Materials and Methods. Glyceraldehyde-3-phosphate dehydrogenase (GAPDH) was detected to indicate the relative amounts of loaded proteins. The results shown are representative of three independent experiments. Statistically different at ${ }^{\#} p<0.05$, \# $p<0.01$, and ${ }^{\# \#} p<0.005$ compared to the control, and at $* p<0.05,{ }^{*} p<0.05$ and ${ }^{* * *} p<0.001$ compared to values at $12.5,25$ and $50 \mu M$ enoxacin, respectively.

UVA irradiation. UVA irradiation of cells was performed using six parallel FL20SBLB fluorescent lamps (Toshiba, Tokyo, Japan) with a peak emission frequency of $352 \mathrm{~nm}$ at a distance of approximately $20 \mathrm{~cm}$. The irradiation intensity was measured using a radiometer (UVR-305/365; Toshiba, Kanagawa, Japan), which was placed at the same distance from the UVA source as the cells. UVA irradiation was applied for $10 \mathrm{~min}$ to $40 \mathrm{~min}$ in the presence of $100 \mu \mathrm{M}$ enoxacin.

Annexin $V$ and dead cell assay. Live and apoptotic cell numbers were determined using the MUSE Annexin V and Dead Cell Kit (Merck Millipore KGaA, Darmstadt, Germany) according to the manufacturer's instructions. Briefly, cells were seeded at a density of $2.0 \times 10^{5}$ cells/well in 6 -well plates. After $12 \mathrm{~h}$, enoxacin was added to each well to a final concentration of $100 \mu \mathrm{M}$ and the cells were then exposed to UVA for 10 to $40 \mathrm{~min}$ or not, then incubated in a $\mathrm{CO}_{2}$ incubator for different periods of time $(0,2,4$ and $6 \mathrm{~h})$ before analysis. The cells were then washed twice with phosphatebuffered saline, trypsinized, and mixed with reagents from the Muse Annexin V and Dead Cell Assay Kit. A MUSE Cell Analyzer was used for data acquisition and analysis; assays were conducted in triplicate.

Western blot analysis. Cells were seeded at a density of $5.0 \times 10^{5}$ cells/well in 6-well plates. After $12 \mathrm{~h}, 100 \mu \mathrm{M}$ enoxacin was added to each well and then cells were exposed to UVA or not then incubated in a $\mathrm{CO}_{2}$ incubator for $4 \mathrm{~h}$. The cells were washed twice 
with phosphate-buffered saline and then lysed with RIPA buffer (Thermo Fisher Scientific, San Jose, CA, USA) containing a protease/phosphatase inhibitor cocktail (Cell Signaling Technology, Beverly, MA, USA). Aliquots of protein $(30-40 \mu \mathrm{g})$ were then resolved on $12 \%$ gels, transferred to a polyvinylidene difluoride membrane, and incubated with primary antibodies specific to poly (ADP-ribose) polymerase (PARP, 1:1,000 dilution), cleaved PARP (1:1000 dilution), and to glyceraldehyde-3-phosphate dehydrogenase (GAPDH, 1:10,000 dilution) (Cell Signaling Technology Inc., Beverly, MA, USA) for $1 \mathrm{~h}$. Then the membrane was washed and incubated with enzyme-conjugated secondary antibodies for $1 \mathrm{~h}$. Finally, proteins were detected using a chemiluminescence reagent (GE Healthcare, Piscataway, NJ, USA).

Effects of reactive oxygen species (ROS) scavengers. To determine whether ROS, including singlet oxygen, superoxide radicals and hydroxyl radicals, were involved in the induction of apoptosis by enoxacin combined with UVA irradiation, the effects of ROS scavengers on apoptosis were investigated $(11,12)$. Briefly, cells were seeded at a density of $2.0 \times 10^{5}$ cells/well in 6 -well plates. After $12 \mathrm{~h}, 100 \mu \mathrm{M}$ enoxacin and individual scavenger $(100 \mu \mathrm{M}$ histidine, $100 \mu \mathrm{M} \mathrm{NaN} N_{3}, 150$ unit/ml SOD and $100 \mu \mathrm{M}$ mannitol) were added to each well and the cells were then exposed to UVA or not then incubated in a $\mathrm{CO}_{2}$ incubator for $4 \mathrm{~h}$. The cells were then washed twice with phosphate-buffered saline, trypsinized, and mixed with reagents from the Muse Annexin V and Dead Cell Assay Kit. A MUSE Cell Analyzer was used for data acquisition and analysis; assays were conducted in triplicate.

Statistical analysis. Statistical analyses of differences were performed by one-way ANOVA followed by a modified Fisher's least square difference method.

\section{Results}

Effects of enoxacin combined with UVA irradiation on apoptosis. To investigate the effects of enoxacin with or without UVA irradiation on apoptosis of AsPC1 cells, cells were treated with $100 \mu \mathrm{M}$ enoxacin for $4 \mathrm{~h}$ after UVA irradiation for 10, 20, 30, and $40 \mathrm{~min}$ (Figure 1A). Enoxacin combined with UVA irradiation increased apoptotic (annexin V-positive) cells in a time-dependent manner. We also investigated the effects of incubation time on apoptosis by treating cells with $100 \mu \mathrm{M}$ enoxacin and incubating them in a $\mathrm{CO}_{2}$ incubator for $0,2,4$, and $6 \mathrm{~h}$ after $20 \mathrm{~min}$ UVA irradiation (Figure 1B). Although treatment with UVA irradiation or enoxacin alone had little effect on apoptosis, even up to an incubation time of $6 \mathrm{~h}$, enoxacin combined with UVA irradiation significantly increased annexin Vpositive cells $2 \mathrm{~h}$ after UVA irradiation. At $6 \mathrm{~h}$ after UVA irradiation, annexin $\mathrm{V}$-positive cells were increased by up to $64 \%$. In addition, these effects were also concentrationdependent (Figure 1C). Moreover, the combined treatment induced PARP cleavage (Figure 1D). These results demonstrated that enoxacin combined with UVA irradiation induced apoptosis of AsPC1 cells in time- and concentrationdependent manners.

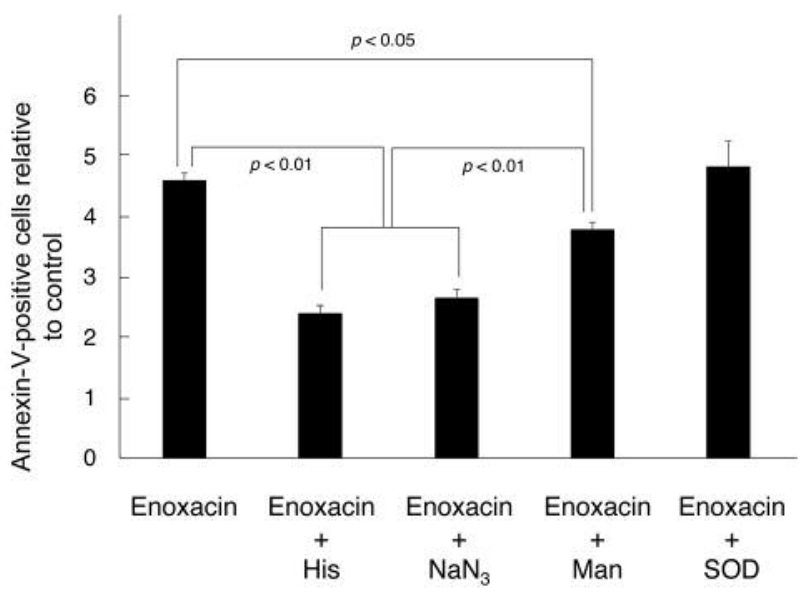

Figure 2. Effects of reactive oxygen species (ROS) scavengers on apoptosis induction in AsPC1 cells. Cells were treated without or with 12.5, 25, 50, and $100 \mu M$ enoxacin under 20 min UVA irradiation. Treated cells at $4 h$ after $U V$ irradiation were applied for the experiment. The value of each bar indicates the mean of three independent experiments. His: Histidine; Man: mannitol; SOD: superoxide dismutase.

Effects of ROS scavengers on apoptosis. To determine whether ROS were involved in the induction of apoptosis by enoxacin combined with UVA irradiation, we examined the effects of ROS scavengers on apoptosis (Figure 2). Histidine and $\mathrm{NaN}_{3}$, scavengers of singlet oxygen, significantly suppressed apoptosis induced by enoxacin and UVA irradiation. Mannitol, a scavenger of hydroxy radical, also slightly suppressed apoptosis. In contrast, SOD did not appear to affect the induction of apoptosis.

\section{Discussion}

In this study, we explored the effects of enoxacin combined with UVA irradiation on human pancreatic cancer cells. Treatment with enoxacin alone did not induce apoptosis, and had little effect on cellular proliferation until $72 \mathrm{~h}$ (data not shown). These results indicate that enoxacin does not have antitumor or cytotoxic activity. UVA irradiation alone also did not induce apoptosis of AspC1 cells, thereby demonstrating that UVA irradiation alone was mild enough not to damage the cells. Interestingly, UVA irradiation in the presence of enoxacin significantly induced apoptosis of AsPC1 cells. This apoptosis induction was considered to be due to some form of UVA activation of enoxacin because apoptosis was observed in UVA irradiation time-dependent and enoxacin concentration-dependent manners, whereas UVA alone did not have any effect up to $40 \mathrm{~min}$.

How is enoxacin activated by UVA irradiation? Previously, the phototoxicity of another new quinolone was thought to be due to ROS generation by UV exposure; 
however, the details underlying this remain unknown (13). Therefore, we investigated the effects of histidine and NaN3 as scavengers of singlet oxygen, mannitol as a scavenger of hydroxy radical, and SOD as a scavenger of superoxide anion on apoptosis induced by enoxacin with UVA irradiation $(11,12)$. Histindine and $\mathrm{NaN}_{3}$ significantly suppressed apoptosis induced by enoxacin combined with UVA irradiation, suggesting the involvement of singlet oxygen. The effects of mannitol and SOD were weak and not observed respectively. These results indicate that the induction of apoptosis in AsPC1 cells by enoxacin with UVA irradiation mainly involves ROS, especially singlet oxygen.

The results of this study suggest that the combination of enoxacin with UVA irradiation may be a useful method for treating pancreatic cancer. Future experiments are needed to determine if other quinolones may also have therapeutic effects against this disease.

\section{References}

1 Conroy T, Desseigne F, Ychou M, Bouche O, Guimbaud R, Becouarn Y, Adenis A, Raoul JL, Gourgou-Bourgade S, de la Fouchardiere C, Bennouna J, Bachet JB, Khemissa-Akouz F, Pere-Verge D, Delbaldo C, Assenat E, Chauffert B, Michel P, Montoto-Grillot $\mathrm{C}$ and Ducreux M: Folfirinox versus gemcitabine for metastatic pancreatic cancer. N Engl J Med 364(19): 1817$1825,2011$.

2 Von Hoff DD, Ervin T, Arena FP, Chiorean EG, Infante J, Moore M, Seay T, Tjulandin SA, Ma WW, Saleh MN, Harris M, Reni M, Dowden S, Laheru D, Bahary N, Ramanathan RK, Tabernero J, Hidalgo M, Goldstein D, Van Cutsem E, Wei X, Iglesias J and Renschler MF: Increased survival in pancreatic cancer with nabpaclitaxel plus gemcitabine. N Engl J Med 369(18): 1691-1703, 2013.

3 Burger PM and Simons JW: Mutagenicity and carcinogenicity of 8-MOP/UVA in cell cultures. Bull Cancer 65(3): 281-282, 1978.

4 Epstein JH: Photocarcinogenesis, skin cancer, and aging. J Am Acad Dermatol 9(4): 487-502, 1983.
5 Nishisgori C: Current concept of photocarcinogenesis. Photochem Photobiol Sci 14(9): 1713-1721, 2015.

6 Kimura H, Lee C, Hayashi K, Yamauchi K, Yamamoto N, Tsuchiya H, Tomita K, Bouvet M and Hoffman RM: UV light killing efficacy of fluorescent protein-expressing cancer cells in vitro and in vivo. J Cell Biochem 110(6): 1439-1446, 2010.

7 Kawabe Y, Mizuno N and Sakakibara S: Photoallergic reaction caused by enoxacin. Photodermatol 6(1): 57-59, 1989.

8 Chen YK, Senadi GC, Lee CH, Tsai YM, Chen YR, Hu WP, Chou YW, Kuo KK and Wang JJ: Apoptosis induced by 2-aryl benzothiazole-mediated photodynamic therapy in melanomas via mitochondrial dysfunction. Chem Res Toxicol 27(7): 1187-1198, 2014.

9 Finlan LE, Kernohan NM, Thomson G, Beattie PE, Hupp TR and Ibbotson SH: Differential effects of 5-aminolaevulinic acid photodynamic therapy and psoralen + ultraviolet a therapy on p53 phosphorylation in normal human skin in vivo. Br $\mathrm{J}$ Dermatol 153(5): 1001-1010, 2005.

10 Tringali G, Sampaolese B and Clementi ME: Expression of early and late cellular damage markers by ARPE-19 cells following prolonged treatment with UV-A radiation. Mol Med Rep 14(4): 3485-3489, 2016.

11 Hachimine K, Shibaguchi H, Kuroki M, Yamada H, Kinugasa T, Nakae Y, Asano R, Sakata I, Yamashita Y, Shirakusa T and Kuroki M: Sonodynamic therapy of cancer using a novel porphyrin derivative, DCPH-p-Na(i), which is devoid of photosensitivity. Cancer Sci 98(6): 916-920, 2007.

12 Li B, Gutierrez PL, Amstad P and Blough NV: Hydroxyl radical production by mouse epidermal cell lines in the presence of quinone anti-cancer compounds. Chem Res Toxicol 12(11): 1042-1049, 1999.

13 Jantova S, Mrvova N, Hudec R, Sedlak J, Panik M and Milata $\mathrm{V}$ : Pro-apoptotic effect of new quinolone 7- ethyl 9-ethyl-6-oxo6,9-dihydro[1,2,5] selenadiazolo [3,4-h]quinoline-7-carboxylate on cervical cancer cell line HeLa alone/with uva irradiation. Toxicol In Vitro 33: 35-44, 2016.

Received August 7, 2017

Revised August 25, 2017

Accepted August 29, 2017 